\title{
Influence of Natural Organic Matter Fouling and Osmotic Backwash on Pressure Retarded Osmosis Energy Production from Natural Salinity Gradients
}

\author{
Ngai Yin Yip and Menachem Elimelech* \\ Department of Chemical and Environmental Engineering, Yale University, New Haven, Connecticut 06520-8286, United States
}

Supporting Information

\begin{abstract}
Pressure retarded osmosis (PRO) has the potential to produce clean, renewable energy from natural salinity gradients. However, membrane fouling can lead to diminished water flux productivity, thus reducing the extractable energy. This study investigates organic fouling and osmotic backwash cleaning in PRO and the resulting impact on projected power generation. Fabricated thin-film composite membranes were fouled with model river water containing natural organic matter. The water permeation carried foulants from the feed river water into the membrane porous support layer and caused severe water flux decline of $\sim 46 \%$. Analysis of the water flux behavior revealed three phases in membrane support layer fouling. Initial foulants of the first fouling phase quickly adsorbed at the active-support layer interface and caused a significantly greater increase in hydraulic resistance than the subsequent second and third phase foulants. The water permeability of the fouled membranes was lowered by $\sim 39 \%$, causing $\sim 26 \%$ decrease in projected power density. A brief, chemical-free osmotic backwash was demonstrated to be

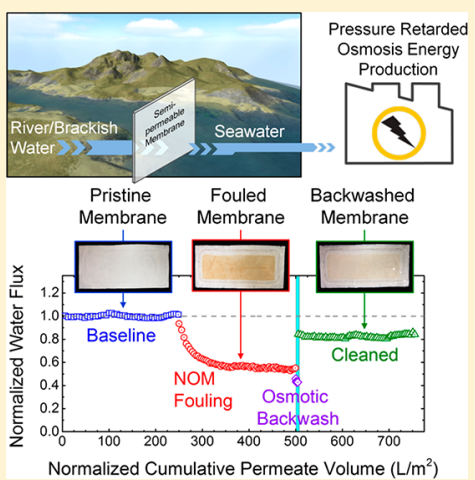
effective in removing foulants from the porous support layer, achieving $\sim 44 \%$ recovery in projected power density. The substantial performance recovery after cleaning was attributed to the partial restoration of the membrane water permeability. This study shows that membrane fouling detrimentally impacts energy production, and highlights the potential strategies to mitigate fouling in PRO power generation with natural salinity gradients.
\end{abstract}

\section{INTRODUCTION}

The impetus to shift to a sustainable energy future has invigorated research and stimulated the development of alternative power sources. ${ }^{1}$ Natural salinity gradients have been identified as a promising source of renewable and emission-free energy. ${ }^{2}$ The free energy of mixing that is released when two solutions of different salt concentration are combined can be harnessed for power generation. ${ }^{3}$ With up to $0.77 \mathrm{~kW} \mathrm{~h}(2.77 \mathrm{MJ})$ of energy produced when a cubic meter of fresh river water mixes with the ocean, ${ }^{4}$ the $\sim 37300 \mathrm{~km}^{3}$ annual global river discharge ${ }^{5}$ represents a potentially enormous source of renewable energy that can contribute to meeting our energy challenges of today and tomorrow.

Pressure retarded osmosis (PRO) is one of the proposed technologies to harvest this sustainable energy source. ${ }^{2,6-8}$ In PRO salinity power generation, the river water "feed solution" is separated from the seawater "draw solution" by a semipermeable membrane. The salt concentration difference provides the osmotic driving force for water permeation from the dilute feed solution into the concentrated draw solution, while solutes are retained by the salt-selective membrane. A hydraulic pressure lower than the osmotic pressure difference builds up on the draw solution, thereby "retarding" water flux across the membrane, and a hydroturbine extracts work from the expanding draw solution volume.

Our recent study analyzed the thermodynamics of the process and showed that PRO can convert the energy of mixing into useful work with high energy efficiency. By utilizing a tenth of the global river water discharge, $157 \mathrm{GW}$ of renewable power can be potentially generated, equivalent to the electrical consumption of approximately half a billion people. ${ }^{4}$ In 2009 , the world's first PRO pilot power plant was inaugurated in Norway, demonstrating the prospective viability of the process. ${ }^{7}$ The venture further targets a $2 \mathrm{MW}$ pilot project in Sunndalsøra to be operational in 2016. ${ }^{9}$ At the same time, realization of cost-effective osmotic power production was bolstered by the recent development of thin-film composite PRO membranes with transport and structural properties capable of high power densities. ${ }^{10-12}$

Fouling is a key issue restricting the efficient performance of membrane processes. ${ }^{13,14}$ In conventional pressure-driven processes, such as ultrafiltration and reverse osmosis, membrane fouling has been extensively studied and shown to reduce water flux productivity, deteriorate permeate quality, increase energy consumption and treatment cost, and shorten membrane life span. ${ }^{13-15}$ The ubiquity of foulants, such as organic matter present in natural waters, alludes that PRO will face comparable problems that impede process productivity. Fouling studies in forward osmosis, a related osmotically driven

\section{Received: July 22, 2013}

Revised: September 9, 2013

Accepted: September 19, 2013

Published: September 19, 2013 
process, and more recently in PRO found similar water flux decline and performance deterioration that supports the notion. ${ }^{16-22}$ Because foulants are brought into the support layer of the membrane by water permeation in PRO, fouling will occur uncharacteristically within the membrane porous support, rather than typically on the membrane surface. This unique circumstance sets PRO apart from other fouling phenomena and is the focus of this current investigation.

In this study we present a systematic investigation of natural organic matter (NOM) fouling and membrane cleaning in PRO power generation. Hand-cast thin-film composite membranes were fouled with model river water containing natural organic matter. Careful characterizations were performed to examine the effects of support layer fouling on the membrane intrinsic transport and structural parameters. The water flux behavior during fouling was analyzed and reconciled with the changes in membrane properties. Based on the experimental findings and drawing upon established membrane fouling concepts, a mechanistic account of the PRO fouling phenomenon was proposed. Osmotic backwash membrane cleaning was then carried out on the fouled membranes, and the performance recovery was methodically quantified to assess the efficiency and suitability of backwashing for potential application. Finally, the power densities of the pristine, fouled, and cleaned membranes were evaluated and the implications for power generation from natural salinity gradients are discussed. This investigation aims to enhance our fundamental understanding of natural organic matter fouling in PRO, provide pertinent insights on the influence of fouling and cleaning on PRO power generation, and highlight the key considerations in the formulation of fouling mitigation strategies necessary to advance the technology.

\section{MATERIALS AND METHODS}

Materials and Chemicals. All chemicals used were analytical grade. For membrane fabrication, polysulfone (PSf) beads $\left(M_{\mathrm{n}}: 22000 \mathrm{Da}\right)$, 1-methyl-2-pyrrolidinone (NMP, anhydrous, 99.5\%), 1,3-phenylenediamine (MPD, >99\%), and 1,3,5-benzenetricarbonyl trichloride (TMC, 98\%) were used as received (Sigma-Aldrich, St. Louis, MO). TMC was dissolved in Isopar-G, a proprietary nonpolar organic solvent (Univar, Redmond, WA $)$. A thin $(\sim 40 \mu \mathrm{m})$, open structure polyester nonwoven fabric (PET, grade 3249, Ahlstrom, Helsinki, Finland) was used as a backing layer for the PSf supports.

Stock solutions of concentrated sodium chloride $(\mathrm{NaCl}, \mathrm{J} . \mathrm{T}$. Baker, Phillipsburg, $\mathrm{NJ})$, sodium bicarbonate $\left(\mathrm{NaHCO}_{3}\right.$, Sigma-Aldrich), and calcium chloride $\left(\mathrm{CaCl}_{2}\right.$, Sigma-Aldrich) were prepared by dissolving the appropriate salts in deionized (DI) water (Milli-Q Millipore, Billerica, MA) and then filtered through a $0.45 \mu \mathrm{m}$ membrane (cellulose acetate, Corning, Corning, NY). Appropriate volumes of the concentrated stock solutions were dosed into deionized (DI) water to achieve the required feed and draw solution composition for the membrane characterization and PRO experiments.

Suwannee river natural organic matter (SRNOM, International Humic Substances Society, St. Paul, MN), an extensively studied membrane organic foulant, ${ }^{23-25}$ was employed as the model foulant to represent natural organic matter in rivers. The characteristics of SRNOM can be found elsewhere. ${ }^{26,27}$ Stock solutions for SRNOM (nominally $500 \mathrm{mg} / \mathrm{L}$ ) were prepared by dissolving the as-received SRNOM powder in DI water adjusted to $\mathrm{pH} 9$ with sodium hydroxide, filtered through a low-binding $0.45 \mu \mathrm{m}$ cellulose acetate membrane to remove the nondissolved fraction, and then stored at $4{ }^{\circ} \mathrm{C}$.

Thin-Film Composite Pressure Retarded Osmosis Membrane Fabrication. Hand-cast thin-film composite (TFC) PRO membranes were fabricated adapting the procedure outlined in our previous publications. ${ }^{10,28,29}$ Briefly, a commercial polyester nonwoven fabric (PET, grade 3249, Ahlstrom, Helsinki, Finland) was taped on a glass plate and then wetted with NMP. Polymer dope solution, prepared by dissolving PSf beads in NMP at 12 wt \%, was then drawn down the PET fabric using a casting knife (Gardco, Pompano Beach, FL) with an adjustable gate height fixed at $250 \mu \mathrm{m}$ ( $\sim 10$ mils $)$. The whole composite was immediately immersed in a DI water precipitation bath at room temperature to initiate non-solventinduced phase separation. ${ }^{13}$ The support membrane remained in the precipitation bath for $10 \mathrm{~min}$ before being transferred to a DI water bath for storage until polyamide (PA) formation.

An interfacial polymerization protocol between MPD and TMC was employed to form the highly cross-linked polyamide thin film on top of the hand-cast PSf support layers. ${ }^{30}$ In short, the top surface of the porous support membrane was soaked in an aqueous MPD solution (3.4 wt \% in DI water) and then contacted with TMC dissolved in Isopar-G at 0.15 wt \% to initiate the formation of the ultrathin selective layer. Following this reaction, the membrane was cured in DI water at $95{ }^{\circ} \mathrm{C}$ for $120 \mathrm{~s}$, rinsed with a $200 \mathrm{ppm} \mathrm{NaOCl}$ aqueous solution for 120 $\mathrm{s}$, then soaked in a $1000 \mathrm{ppm} \mathrm{NaHSO}_{3}$ aqueous solution for 30 $\mathrm{s}$, before a final wet curing step at $95{ }^{\circ} \mathrm{C}$ for $120 \mathrm{~s}$. The nascent TFC membranes were rinsed thoroughly and stored in DI water at $4{ }^{\circ} \mathrm{C}$. Prior to testing, the fabricated membranes were immersed in $25 \mathrm{wt} \%$ isopropanol for $30 \mathrm{~min}$ to wet the pores of the membrane support layer, and then rinsed thoroughly with DI water.

Membrane Characterization. The water permeability, $A$, salt permeability, $B$, coefficients of the polyamide active layers, and the structural parameter, $S$, of the membrane support layers were determined using a protocol adapted from our recently developed forward osmosis (FO) membrane characterization methodology. ${ }^{31}$ Membrane characterizations were performed in a laboratory-scale experimental setup (Supporting Information, Figure S1) described in our previous studies. ${ }^{10,28,29}$ The custom-built cell has an effective membrane area of 20.02 $\mathrm{cm}^{2}$ on both sides. The feed and draw solutions were circulated in concurrent crossflow at a velocity of $10.7 \mathrm{~cm} / \mathrm{s}$ in closed loops. Channel spacers were not employed to avoid the possible introduction of confounding factors caused by altered hydrodynamics. Temperature of the system was maintained at $25 \pm 0.5{ }^{\circ} \mathrm{C}$ for all characterization experiments. Details of the method are presented in the Supporting Information.

The hand-cast membranes were characterized in PRO configuration, i.e., porous support layer facing the feed solution and active layer facing the draw solution, without applied hydraulic pressure. Membrane characterization experiments comprised eight stages where the water and salt fluxes $\left(J_{\mathrm{w}}\right.$ and $J_{s}$, respectively) were measured as the concentration difference across the membrane was varied by changing the draw and feed solution salt concentrations at each stage. PRO water and salt flux governing equations, that incorporates the performance limiting phenomena of external concentration polarization (ECP), internal concentration polarization (ICP), and reverse permeation of draw salt, were developed in our previous publication: ${ }^{10}$ 


$$
\begin{aligned}
& J_{\mathrm{w}}=A\left\{\frac{\pi_{\mathrm{D}} \exp \left(-\frac{J_{\mathrm{w}}}{k}\right)-\pi_{\mathrm{F}} \exp \left(\frac{J_{\mathrm{w}} S}{D}\right)}{1+\frac{B}{J_{\mathrm{w}}}\left[\exp \left(\frac{J_{\mathrm{w}}}{D}\right)-\exp \left(-\frac{J_{\mathrm{w}}}{k}\right)\right]}-\Delta P\right\} \\
& J_{\mathrm{s}}=B\left\{\frac{c_{\mathrm{D}} \exp \left(-\frac{J_{\mathrm{w}}}{k}\right)-c_{\mathrm{F}} \exp \left(\frac{J_{\mathrm{w}} S}{D}\right)}{1+\frac{B}{J_{\mathrm{w}}}\left[\exp \left(\frac{J_{\mathrm{w}}}{D}\right)-\exp \left(-\frac{J_{\mathrm{w}}}{k}\right)\right]}\right\}
\end{aligned}
$$

where $c_{\mathrm{D}}$ and $c_{\mathrm{F}}$ are the draw and feed solution salt concentrations, respectively, $\pi_{\mathrm{D}}$ and $\pi_{\mathrm{F}}$ are the osmotic pressures of the bulk draw and feed solutions, respectively, $k$ is the ECP boundary layer mass transfer coefficient, $D$ is the bulk diffusion coefficient of the solute, and $\Delta P$ is the hydraulic pressure applied on the draw solution. The membrane properties were numerically determined by solving the system of water and salt flux equations, through nonlinear regression of the fitting parameters $A, B$, and $S$ to the measured $J_{\mathrm{w}}$ and $J_{\mathrm{s}}$ (least-squares minimization of the residuals method). Each hand-cast membrane was characterized three times: before the fouling experiment (pristine), after SRNOM fouling in PRO (fouled), and after osmotic backwash (cleaned).

Membrane Fouling Protocol. PRO fouling experiments were carried in the same setup described in the characterization procedure with Suwannee river natural organic matter as the model organic foulant. The hand-cast TFC membranes were oriented in PRO mode (i.e., porous support layer faces feed and active layer faces draw) and no hydraulic pressure was applied. The experimental feed solution pressure (i.e., no applied hydraulic pressure) simulates actual PRO operating conditions, where the draw side is pressurized while the feed side is at ambient pressure. Initially the system was equilibrated by circulating DI water across both sides of the membrane. To initiate the fouling run, appropriate amounts of salt and foulant stock solution were dosed into the feed solution to simulate river water $\left(0.4 \mathrm{mM} \mathrm{NaCl}, 0.2 \mathrm{mM} \mathrm{NaHCO} 3,0.3 \mathrm{mM} \mathrm{CaCl}_{2}\right.$, and $20 \mathrm{mg} / \mathrm{L}$ (nominal) SRNOM; $\mathrm{pH}=6.96$, total ionic strength $=1.5 \mathrm{mM}$ ), while concentrated $\mathrm{NaCl}$ stock solution was added to the draw side to simulate seawater. Membrane properties determined in the earlier characterization were used with eq 1 to calculate the salt concentration of the model seawater draw solution required to obtain an initial water flux of $25 \mathrm{~L} \mathrm{~m}^{-2} \mathrm{~h}^{-1}$.

As water permeates across the membrane during the experiment, the osmotic driving force gradually declines as the model seawater draw solution is diluted by the permeated water. Baseline experiments, where the SRNOM foulant was left out of the model river water solution chemistry, were conducted before the fouling run to establish the flux decline due to the effect of draw solution dilution. Another foulant-free experiment was repeated after osmotic backwashing (described in next subsection) to determine the recovery in water flux performance of the cleaned membrane. For each membrane, the same initial draw solution concentration was employed for the baseline, fouling, and cleaned experimental runs. The experiments were terminated when the cumulative permeate volume reaches $250 \mathrm{~L}$ per square meter of membrane area ( $\sim 500 \mathrm{~mL}$ of permeate). The fouling experimental runs took around $20 \mathrm{~h}$ to complete, while the baseline runs lasted $\sim 12-$ $15 \mathrm{~h}$. Due to the long duration of the experiments, the system experienced wider temperature fluctuations and was, thus, maintained at $25 \pm 1.5{ }^{\circ} \mathrm{C}$.
Osmotic Backwash. The fouled membranes were cleaned by reversing the water flux direction and utilizing the water permeation drag to remove foulants from the porous support. Osmotic backwash was performed by switching the membrane orientation such that the porous support layer faced the draw solution and the active layer was toward the feed solution. ${ }^{32,33}$ The feed and draw streams employed in osmotic backwash were identical to those used for the baseline experiments described earlier (i.e., model river water without SRNOM foulants and $\mathrm{NaCl}$ solution as model seawater, respectively). Osmotic backwash was carried out for $5 \mathrm{~L}$ of cumulative permeate volume per square meter of membrane area (i.e., $2 \%$ of cumulative permeate volume in fouling experiment), and the system temperature was kept at $25 \pm 0.5{ }^{\circ} \mathrm{C}$.

Power Density Projection. The membrane power density, $W$, is defined as the power generated per unit membrane area and is equal to the rate of increase in the draw solution volume per unit membrane area (i.e., water flux across the membrane, $J_{\mathrm{w}}$ ) multiplied by the hydraulic pressure applied on the draw side, $\Delta P$

$$
W=J_{\mathrm{w}} \Delta P
$$

The membrane power density is a crucial factor affecting the cost-effectiveness, and hence the economical feasibility, of PRO energy production with natural salinity gradients. ${ }^{34,35}$ An examination of eqs 1 and 3 indicates that the power density is determined by the membrane characteristic parameters: water permeability, $A$, salt permeability, $B$, and the structural parameter, $S$. As such, the transport and structural properties determined in the membrane characterization can be used to project the highest power density attainable by the membrane in PRO, ${ }^{10,36}$ and to quantify the effect of SRNOM fouling and osmotic backwash on the energy production efficiency of the process.

\section{RESULTS AND DISCUSSION}

Fabricated Membrane Transport and Structural Parameters. Discussion on the characteristics of the handcast membranes is detailed in the Supporting Information, together with representative scanning electron microscope (SEM) cross-sectional images (Figure S2). The FO characterization protocol presented in our recent publication ${ }^{31}$ was adopted and modified for PRO to determine the active layer transport properties and support layer structural parameter intrinsic to the membrane. Table 1 presents the water permeability, $A$, salt permeability, $B$, and structural parameter, $S$, of duplicate hand-cast membranes (TFC-PRO \#A and \#B). The membrane duplicates possessed similar characteristic parameters, within experimental variations of the hand-casting fabrication technique, and are comparable to literature. ${ }^{29}$ Figure S3 of the Supporting Information shows the experimental fluxes measured in the characterization experiments and the ratios of $J_{\mathrm{w}}$ to $J_{\mathrm{s}}$ (i.e., reverse flux selectivity) in the first four stages of the protocol. The water and salt fluxes predicted by the calculated membrane parameters in Table 1 are in excellent agreement with experimental measurements for both membrane duplicates, (coefficients of determination, $R^{2}$, are between 0.965 and 0.999), indicating robustness of the characterization technique to accurately determine membrane properties. Further details on the characterization protocols are elaborated in the Supporting Information.

NOM Fouling of Membrane Support Layer Substantially Reduces Water Flux. The PRO water flux of hand-cast 
Table 1. Characteristic Transport Properties and Structural Parameter of the Fabricated Membranes before the Organic Fouling Experiment with SRNOM (i.e., pristine), after SRNOM Fouling, and after Osmotic Backwash (i.e., cleaned)

\begin{tabular}{|c|c|c|c|}
\hline & $\begin{array}{l}\text { water permeability, } \\
A\left(\mathrm{~L} \mathrm{~m}^{-2} \mathrm{~h}^{-1} \text { bar }^{-1}\right)\end{array}$ & $\begin{array}{c}\text { salt }(\mathrm{NaCl}) \\
\text { permeability, } \\
B\left(\mathrm{~L} \mathrm{~m}^{-2} \mathrm{~h}^{-1}\right)\end{array}$ & $\begin{array}{c}\text { structural } \\
\text { parameter, } \\
S(\mu \mathrm{m})\end{array}$ \\
\hline \multicolumn{4}{|c|}{ TFC-PRO Membrane \#A } \\
\hline Pristine & 1.59 & 0.087 & 479 \\
\hline $\begin{array}{l}\text { Fouled } \\
\qquad\left(\% \text { change }^{a}\right)\end{array}$ & $0.96(-39.6 \%)$ & 0.066 & 431 \\
\hline $\begin{array}{l}\text { Cleaned } \\
\quad\left(\% \text { recovery }{ }^{b}\right)\end{array}$ & $1.21(+39.7 \%)$ & 0.087 & 434 \\
\hline \multicolumn{4}{|c|}{ TFC-PRO Membrane \#B (duplicate) } \\
\hline Pristine & 1.54 & 0.060 & 531 \\
\hline $\begin{array}{l}\text { Fouled } \\
\left.\qquad \% \text { change }^{a}\right)\end{array}$ & $0.95(-38.3 \%)$ & 0.056 & 503 \\
\hline $\begin{array}{l}\text { Cleaned } \\
\quad\left(\% \text { recovery }{ }^{b}\right)\end{array}$ & $1.19(+40.7 \%)$ & 0.069 & 503 \\
\hline
\end{tabular}

${ }^{a}$ Percentage change relative to the water permeability of the pristine membrane. ${ }^{b}$ Percentage of the difference between cleaned and fouled water permeability, to the difference between pristine and fouled water permeability.

membrane \#A, without applied hydraulic pressure and NOM foulant, is presented in Figure 1A ("Baseline", blue square symbols), as a function of the cumulative permeate volume normalized by the effective membrane area. An $\mathrm{NaCl}$ solution was employed as the model seawater draw solution, while a foulant-free, model river water was used as the feed solution. In the "Baseline" experimental run, the observed decline in $J_{\mathrm{w}}$ is attributed to the diminishing effective osmotic driving force as water permeating over from the feed side dilutes the seawater draw solution (effects of reverse draw salt flux and concentration of feed solution were found to be comparatively small), resulting in reduction of the salt concentration difference across the membrane. At the end of the experiment, the water flux was $20.3 \mathrm{~L} \mathrm{~m}^{-2} \mathrm{~h}^{-1}$, compared with $24.7 \mathrm{~L} \mathrm{~m}^{-2}$ $\mathrm{h}^{-1}$ initially.

During PRO power generation with natural salinity gradients, water permeates from the river water feed solution into the membrane porous support, across the active layer, and into pressurized seawater draw solution (Figure 1B). Therefore, foulants present in the river water will be carried into the membrane support layer by the water permeation. The foulants accumulate within the porous support layer and at the activesupport interface, as they are rejected by the polyamide active layer, and can lead to deterioration of PRO water flux. ${ }^{16,18,21,22}$ Fouling experiment was then performed on the membrane by using the same solution composition and operating conditions (to achieve the same initial $J_{\mathrm{w}}$ of $\sim 25 \mathrm{~L} \mathrm{~m}^{-2} \mathrm{~h}^{-1}$ ), but with 20 $\mathrm{mg} / \mathrm{L}$ (nominal) SRNOM present in the feed solution as the model organic foulant. A yellowish-brown tint was observed in the model river water feed solution in the presence of the organic foulants. Note that although the natural organic matter concentration of the model river water employed here is higher than typical river waters $(2-10 \mathrm{mg} / \mathrm{L})^{37}$ in order to accelerate the fouling study, a recent PRO fouling study demonstrated that the effect of foulant concentration is eliminated when water flux is presented as a function of the foulant loading density. $^{21}$

In the experimental runs presented in the paper, no hydraulic pressure was applied to both the draw and feed sides. In actual
A)

Nominal Foulant Loading Density $\left(\mathrm{g} / \mathrm{m}^{2}\right)$
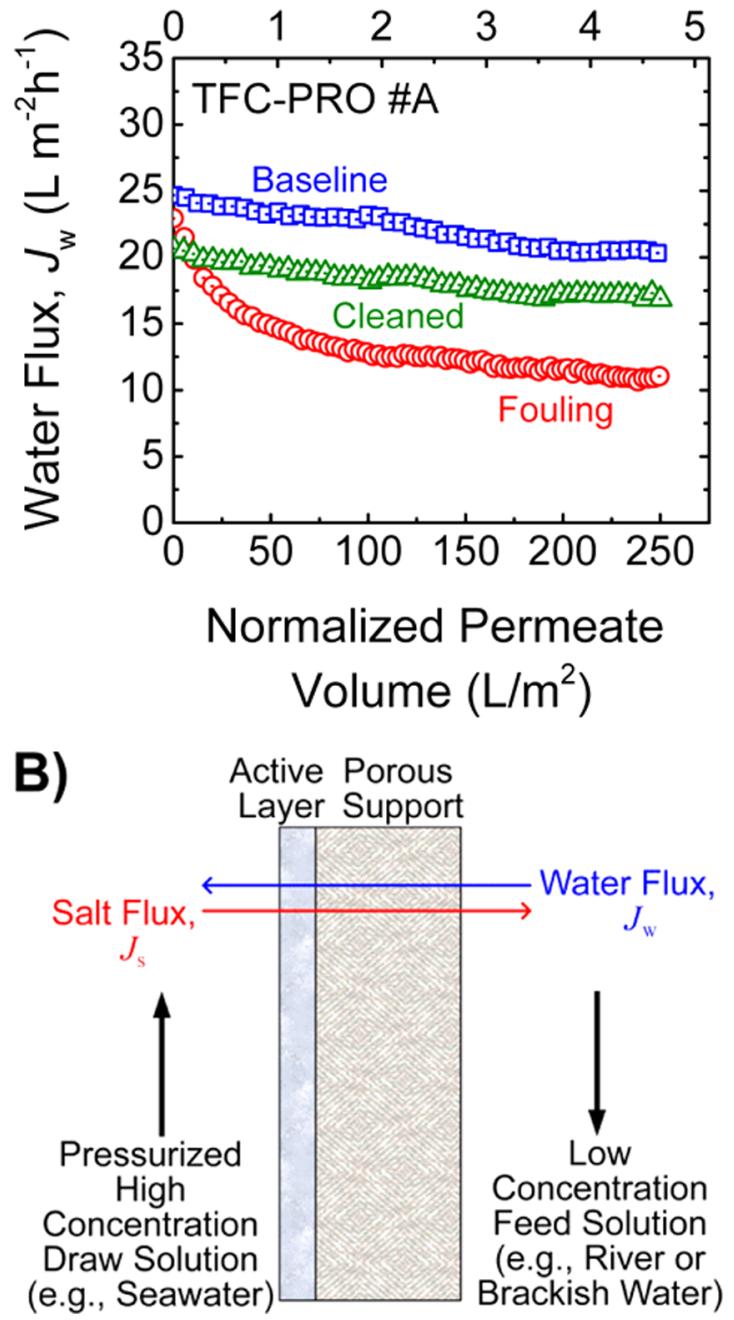

Figure 1. (A) Water fluxes of hand-cast TFC-PRO membrane \#A as a function of the cumulative permeate volume, normalized by the membrane area, in the baseline, fouling, and cleaned membrane experiments (blue square, red circle, and green triangle symbols, respectively). The model river water composition is $0.4 \mathrm{mM} \mathrm{NaCl}, 0.2$ $\mathrm{mM} \mathrm{NaHCO}$, and $0.3 \mathrm{mM} \mathrm{CaCl}_{2}$ (total ionic strength $=1.5 \mathrm{mM}$ ), while the model seawater is a $570 \mathrm{mM} \mathrm{NaCl}$ solution (to obtain an initial water flux of $25 \mathrm{~L} \mathrm{~m}^{-2} \mathrm{~h}^{-1}$ in the baseline run). During the fouling experiment, $20 \mathrm{mg} / \mathrm{L}$ (nominal) SRNOM was additionally introduced to the river water as model foulant (feed solution $\mathrm{pH}=$ 6.98). Crossflow velocity was set at $10.7 \mathrm{~cm} / \mathrm{s}$ in both membrane channels (no spacers) and the system temperature was maintained at $25 \pm 1.5{ }^{\circ} \mathrm{C}$. The top horizontal axis indicates the nominal foulant loading density into the membrane porous support (initial foulant concentration multiplied by permeate volume). (B) Schematic representation of the water flux, $J_{\mathrm{w}}$, and reverse draw solute flux, $J_{\mathrm{s}}$, across a thin-film composite membrane in PRO operating in countercurrent flow. The active layer faces the pressurized high concentration draw solution (e.g., seawater), while the support layer is in contact with the low concentration feed solution (e.g., river or brackish water).

PRO operation, the draw side is pressurized while the feed side is at ambient pressure. Although the experimental conditions do not fully replicate actual operating conditions, the experimental pressure on the feed side (where fouling of the 
membrane support layer occurs) simulates the actual feed solution pressure.

Red circle symbols in Figure 1A ("Fouling") indicates $J_{\mathrm{w}}$ during the organic fouling run over the same cumulative permeate volume. The decline in water flux was substantially greater than that observed in "Baseline". For instance, $J_{\mathrm{w}}$ at end of the fouling run was $11.0 \mathrm{~L} \mathrm{~m}^{-2} \mathrm{~h}^{-1}$, almost half that of the water flux without fouling. This significantly larger drop in water flux is attributed to fouling of the membrane by the SRNOM brought into the porous support layer. Identical water flux trends for the baseline and fouling experimental runs were observed for duplicate membrane \#B (Figure S4 of Supporting Information). The salt concentration of the model seawater draw solution was, likewise, adjusted to obtain an initial $J_{\mathrm{w}}$ of $\sim 25 \mathrm{~L} \mathrm{~m}^{-2} \mathrm{~h}^{-1}$ for TFC-PRO \#B. This allowed the permeation drag force on the foulant toward the membrane, an important factor in membrane fouling, to remain constant for the duplicate experiments. ${ }^{16}$ The decrease in water flux across the NOM fouled membrane is expected to adversely affect the productivity of PRO power generation and is discussed in a later subsection.

Fouling of the porous support by SRNOM can be visualized by inspecting representative images of a TFC-PRO membrane (captured with a digital camera) presented in Figure 2. The left

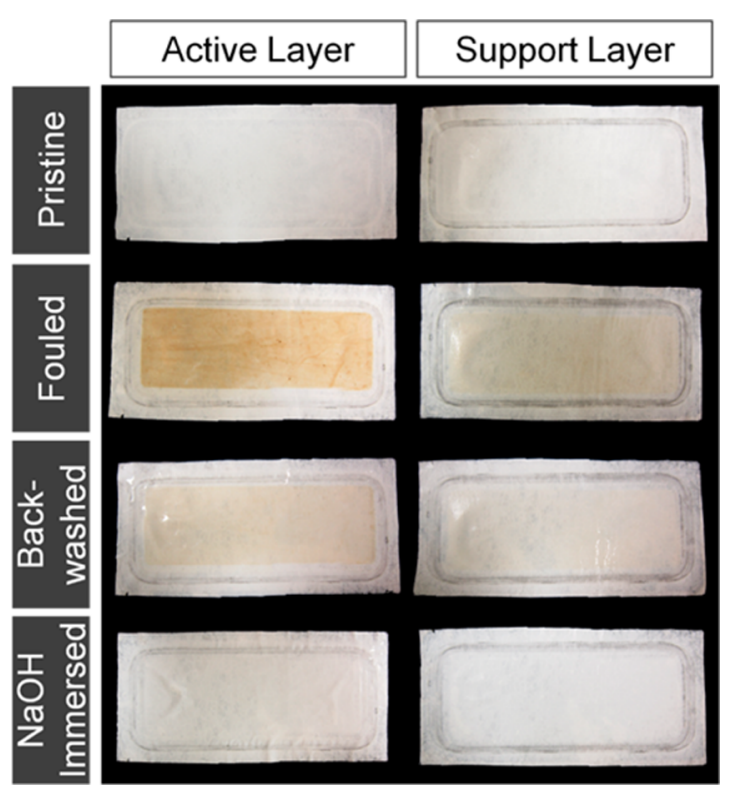

Figure 2. Representative images of the active and support layer of a hand-cast TFC membrane (left and right column, respectively) at various stages of the experimental protocol. The membrane images are for, from top to bottom, pristine condition (after the 1st characterization test), fouled in PRO with an NOM feed solution, after osmotic backwash cleaning, and after $48 \mathrm{~h}$ immersion in $0.1 \mathrm{M} \mathrm{NaOH}$. The images were acquired from a single membrane coupon with a digital camera.

and right columns of image show the active and support sides, respectively, of the hand-cast membrane coupon. Images of the membrane before and after fouling ("Pristine" and "Fouled") are displayed in the first and second rows, respectively. Note that the rounded rectangle around the $77 \mathrm{~mm} \times 26 \mathrm{~mm}$ effective membrane area was imprinted by the gasket of the membrane cell. Qualitative examination of the images reveals informative visual cues that, when applied together with quantitative results, can shed light on the fouling mechanism. We observe that the pristine, unfouled membrane appears white on both the active and support layers, while the effective area of the fouled membrane is distinctly yellowish-brown. Interestingly, the active side exhibited a notably darker hue than the support side, despite the natural organic foulants being loaded into the porous support layer of the membrane. Filtering a fouling feed solution through the porous support (i.e., no polyamide active layer) showed that the bulk of the NOM ( $\sim 78$ wt \%) passed through and only $\sim 22$ wt \% were retained by the highly porous support layer. This observation, together with the greater visual intensity of the foulants on the active side, strongly indicates that most of the SRNOM accumulated at, or very close to, the active-support layer interface.

Water Flux Behavior Indicates Three Phases During Support Layer Fouling. By normalizing the water flux during the fouling run, $J_{\mathrm{w}}$, to the baseline, $J_{\mathrm{w}, 0}$, the effect of draw solution dilution can be separated, thus allowing for the direct examination of the influence of SRNOM membrane fouling on PRO performance. The normalized water flux for hand-cast TFC-PRO membrane \#A is presented in Figure 3 as a function of the cumulative permeate volume divided by the effective membrane area. The blue square and red circle symbols denote "Baseline" and "Fouling" experiments, respectively.

As water permeates across the membrane, foulants from the bulk feed solution are carried into the membrane porous support. Indicated on the top horizontal axis is the nominal foulant loading density during the fouling experiment, defined as the product of the cumulative permeate volume and the bulk feed solution SRNOM concentration divided by the effective membrane area. By measuring the total organic carbon (TOC) of the foulant stock solution, after filtration through a $0.45 \mu \mathrm{m}$ membrane, with a TOC analyzer and assuming the carbon mass of natural organic matter is $50 \%,{ }^{38}$ the dissolved SRNOM concentration in the model river water feed solution was determined to be $18.7 \mathrm{mg} / \mathrm{L}$ (i.e., undissolved fraction is $\sim 1.3$ $\mathrm{mg} / \mathrm{L}$ out of the $20 \mathrm{mg}$ as-received SRNOM added to a liter of DI water). Additionally, TOC measurements of the bulk feed solution before and after the fouling experiments showed that the feed foulant concentration remained practically unchanged despite the $\sim 25 \%$ reduction in feed solution volume at the end of the run, validating the approximation that the foulant mass loaded into the membrane is roughly equivalent to the convective foulant transport (bulk SRNOM concentration multiplied by the cumulative permeate volume).

The water flux behavior of membrane \#A during fouling in PRO is more clearly evident from Figure 3, and can be loosely categorized into three phases. A very steep water flux decline was observed in the initial phase of fouling, with normalized flux dropping by $\sim 23 \%$ in the first $15 \mathrm{~L} / \mathrm{m}^{2}$ of normalized permeate volume (i.e., $250-265 \mathrm{~L} / \mathrm{m}^{2}$ on the bottom horizontal axis). Subsequently, in the second phase, normalized flux declined at a gradually reducing rate for the next $85 \mathrm{~L} / \mathrm{m}^{2}$ permeate volume (that is, $265-350 \mathrm{~L} / \mathrm{m}^{2}$ on the bottom horizontal axis). Beyond $\sim 100 \mathrm{~L} / \mathrm{m}^{2}$ permeate volume (350$500 \mathrm{~L} / \mathrm{m}^{2}$ on the bottom horizontal axis) in the third phase, water flux attrition eased off and the normalized flux ran almost horizontal with the baseline experiment. The eventual relative decrease in PRO water flux due to SRNOM fouling of the membrane was $45.6 \%$. Duplicate hand-cast membrane \#B exhibited identical three-phase trend with almost similar water flux behavior during SRNOM fouling: $\sim 24 \%$ water flux reduction in the initial $15 \mathrm{~L} / \mathrm{m}^{2}$ of permeation, followed by 


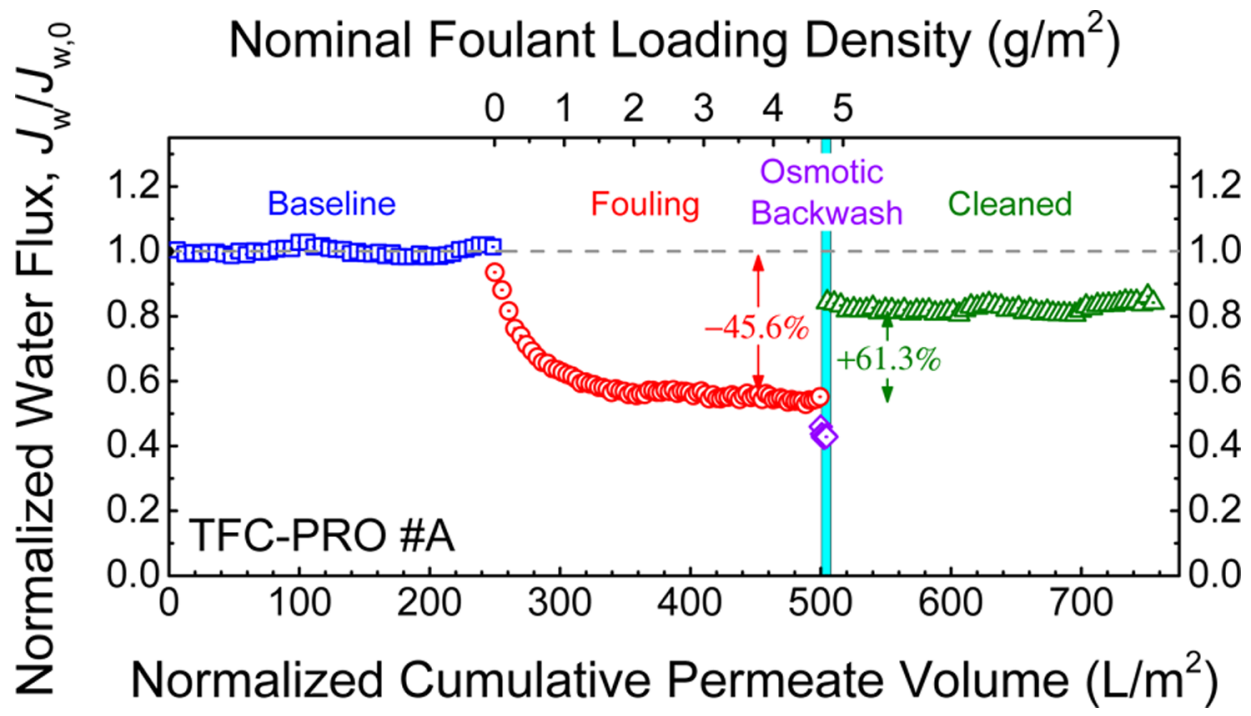

Figure 3. Water flux as a function of the cumulative permeate volume per unit active area of TFC-PRO membrane \#A. The water flux for the baseline, fouling, osmotic backwash, and cleaned experiments (blue square, red circle, violet diamond, and green triangle symbols, respectively) is normalized with the baseline water flux, $J_{\mathrm{w}, 0}$, to account for the dilution of the draw solution. The experimental conditions are described in Figure 1A. Osmotic backwash was performed by switching the feed and draw streams for $5 \mathrm{~L} / \mathrm{m}^{2}$ of normalized cumulative permeate volume. The top horizontal axis indicates the nominal foulant loading density into the membrane porous support (initial foulant concentration multiplied by permeate volume per unit membrane area) during fouling. At the end of the fouling run, normalized water flux declined to $\sim 54.4 \%$ relative to the baseline. Approximately $61.3 \%$ of the water flux is recovered after the quick osmotic backwash.

leveling out of water flux at around $100 \mathrm{~L} / \mathrm{m}^{2}$ permeate volume, and eventual reduction of $-47.5 \%$ in water flux at the end of the run (Figure S5 of Supporting Information).

Initial Foulant Deposition at Active-Support Layer Interface Drastically Lowers Membrane Permeability. Characterization of the membranes after the fouling reveals that the SRNOM deposited in the porous support caused substantial decrease in the active layer water permeability, $A$ (Table 1). The water permeability of hand-cast TFC-PRO membranes \#A and \#B fell by $39.6 \%$ and $38.3 \%$, respectively, while salt permeability, $B$, only dropped slightly. The buildup of natural organic matter inside the membrane adds hydraulic resistance, thereby lowering the water permeability. ${ }^{18,39}$ The governing equation for PRO water flux (eq 1 ) indicates that $J_{\mathrm{w}}$ is directly proportional to $A$. Thus, the increase in hydraulic resistance of the membrane due to the SRNOM fouling is the principal cause of the diminished water flux performance. We also note that the calculated structural parameter, $S$ (characteristic diffusion distance of the support layer), remained practically constant within the accuracy of the characterization method. This observation indicates that the SRNOM foulants did not confer significant impedance to the diffusion of solutes in the support layer.

The immediate sharp decrease in water flux at the start of the fouling experiment followed by the gradual leveling out of the slope indicates that the initial SRNOM contributes disproportionally more to performance deterioration than subsequently loaded foulants. ${ }^{40}$ From the top horizontal axis of Figure 3 and Figure S5 of Supporting Information, the first $0.27 \mathrm{~g} / \mathrm{m}^{2}$ of foulants loaded into the membranes in the initial phase of fouling resulted in a steep and almost linear reduction in $J_{\mathrm{w}}$. As the support layer, by itself, only retains a fraction of the SRNOM molecules ( 22 wt \%), the majority of the initial foulants permeates across the entire support layer and quickly adsorbs onto the effective area of the active layer-porous support interface. We postulate that this fast sorption of foulants drastically exacerbates the hydraulic resistance and leads to a rapid decrease in $A,{ }^{40}$ accounting for the precipitous water flux decline. Subsequent SRNOM that are carried into the porous support by the water permeation are deposited on top the adsorbed foulants, forming a "cake layer". ${ }^{39,41}$ In this second fouling phase, corresponding to the next $1.6 \mathrm{~g} / \mathrm{m}^{2}$ of foulant or $0.27-1.87 \mathrm{~g} / \mathrm{m}^{2}$ on the top horizontal axis, the gentler slope of $J_{\mathrm{w}}$ decrease suggests that the foulant cake layer does not generate as much hydraulic resistance compared to the adsorbed organic matter. ${ }^{40}$ By now, almost all the effective area of the susceptible active-support interface possibly had already been fouled by SRNOM. Hence, for the last fouling phase, only marginal attrition in water flux was observed despite $2.80 \mathrm{~g} / \mathrm{m}^{2}$ of foulant (that is, $1.87-4.67 \mathrm{~g} / \mathrm{m}^{2}$ on the top horizontal axis of Figures 3 and S5) nominally being carried into the porous support. Additionally, the high concentration of SRNOM in the membrane support layer, coupled with lesser permeation drag (i.e., lower water flux), enables greater back diffusion of the foulant molecules back into the bulk feed solution, reducing actual SRNOM deposition in the membrane.

The water permeability of the membrane can be related to the intrinsic hydraulic resistance of the polyamide active layer and the hydraulic resistance of the foulant by Darcy's law: ${ }^{39,40}$

$$
A=\frac{1}{\mu}\left(\frac{1}{R_{\mathrm{m}}}+\frac{1}{R_{\mathrm{f}}}\right)
$$

where $A$ is the membrane water permeability, $\mu$ is the dynamic viscosity of water, $R_{\mathrm{m}}$ is the hydraulic resistance of the pristine polyamide selective layer, and $R_{\mathrm{f}}$ is the hydraulic resistance of the foulant. Utilizing the $A$ value of the pristine membranes in Table 1 and $R_{\mathrm{f}}=0, R_{\mathrm{m}}$ were calculated to be 2.26 and $2.33 \times$ $10^{14} \mathrm{~m}^{-1}$ for hand-cast TFC-PRO \#A and \#B, respectively. Using eq 4 with $R_{\mathrm{m}}$ and the water permeability of the fouled membranes, $R_{\mathrm{f}}$ were determined to be 1.48 and $1.45 \times 10^{14} \mathrm{~m}^{-1}$ for membranes \#A and $\# \mathrm{~B}$, respectively. Thus, the organic matter foulants detrimentally increased the membrane 
hydraulic resistance by over $60 \%$. The foulant specific hydraulic resistance, $r_{\mathrm{f}}$, is defined as the hydraulic resistance per unit mass of foulant $\left(r_{\mathrm{f}}=R_{\mathrm{f}} / m_{\mathrm{f}}\right)$. The average $r_{\mathrm{f}}$ for $4.67 \mathrm{~g} / \mathrm{m}^{2}$ of SRNOM nominally loaded into the membrane support layer is determined to be 3.18 and $3.10 \times 10^{13} \mathrm{~m} / \mathrm{g}$ for duplicate membranes \#A and \#B, respectively.

The same characterizations and fouling experiment were performed on a third hand-cast TFC-PRO membrane, except the fouling run was terminated earlier, after normalized cumulative permeate volume of $15 \mathrm{~L} / \mathrm{m}^{2}$ (equivalent to 0.27 $\mathrm{g} / \mathrm{m}^{2}$ nominal foulant loading density). That is, the membrane experienced only the first phase of fouling, where SRNOM quickly adsorbs onto the effective area of the active-support interface and triggers drastic water flux decline. Water permeability of the pristine and fouled membrane, determined by membrane characterization, was 1.90 and $1.55 \mathrm{~L} \mathrm{~m}^{-2} \mathrm{~h}^{-1}$ $\mathrm{bar}^{-1}$, respectively. The calculated $r_{\mathrm{f}}$, indicative of the adverse effect of SRNOM at the active-support interface, is $15.2 \times 10^{13}$ $\mathrm{m} / \mathrm{g}$, approximately five times the average specific hydraulic resistance of $(3.10-3.18) \times 10^{13} \mathrm{~m} / \mathrm{g}$ in the complete fouling run. This quantitatively reinforces the finding that initial SRNOM foulants deposited in the membrane porous support layer cause severe escalation in membrane hydraulic resistance, thus lowering water permeability and detrimentally reducing water productivity in PRO.

Osmotic Backwash Partially Reverses Fouling. Fouling of thin-film composite membranes in PRO occurs in the membrane porous support which acts as an unstirred boundary layer. Hence, the foulants are sheltered from shear forces induced during physical cleaning (such as increasing the crossflow velocity at the membrane interface), ${ }^{16}$ while the efficacy of chemical cleaning agents will be drastically impeded as the chemicals need to diffuse across the support layer thickness to reach foulants accumulated at active layer interface. Osmotic backwash can circumvent the shielding effect of the porous support. By swapping the feed and draw streams briefly, the direction of water permeation is momentarily reversed and membrane cleaning is initiated. ${ }^{32,33}$ The permeation drag that previously brought SRNOM into the porous support during fouling is now utilized to dislodge the foulants and carry the accumulated organic matter out of the support layer. After the NOM fouled membranes were characterized, a quick osmotic backwash was conducted. The normalized cumulative volume of permeate was $5 \mathrm{~L} / \mathrm{m}^{2}$, corresponding to $2 \%$ of the permeate volume during the entire fouling run. During backwashing, the average nominal permeation velocity (i.e., water flux) was 2.94 and $3.03 \mu \mathrm{m} / \mathrm{s}\left(10.6\right.$ and $\left.10.9 \mathrm{~L} \mathrm{~m}^{-2} \mathrm{~h}^{-1}\right)$ for membranes \#A and $\# B$, respectively. The water flux stabilized quickly in the first few minutes of osmotic backwash and remained fairly constant thereafter.

Foulant-free PRO experiments, with draw and feed solution compositions identical to the baseline experiment (i.e., model seawater and river water), were then carried out on the cleaned membranes to quantify the water flux recovery. Instead of achieving an initial water flux of $\sim 25 \mathrm{~L} \mathrm{~m}^{-2} \mathrm{~h}^{-1}$ as it would if pristine, cleaned membrane \#A started off with $J_{\mathrm{w}}$ of $20.7 \mathrm{~L} \mathrm{~m}^{-2}$ $\mathrm{h}^{-1}$, which eventually decreased to $16.9 \mathrm{~L} \mathrm{~m}^{-2} \mathrm{~h}^{-1}$ due draw solution dilution (Figure 1A, green triangle symbols). The averaged normalized water flux of the cleaned membrane was $82.3 \%$ of the pristine $J_{w}$ (Figure 3). The quick osmotic backwash achieved a partial recovery in water flux of $\sim 61.3 \%$ (defined as $J_{\mathrm{w} \text {,cleaned }}-J_{\mathrm{w} \text {,fouled }}$ divided by $J_{\mathrm{w} \text {,baseline }}-J_{\mathrm{w}, \text { fouled }}$ ), thus demonstrating its effectiveness in reclaiming a considerable portion of the productivity lost to SRNOM fouling of the membrane porous support. Very similar water flux trends were observed for duplicate TFC-PRO membrane \#B: normalized water flux of $78.7 \%$ and $55.3 \%$ recovery after cleaning (Figures S4 and S5 of Supporting Information).

The transport and structural parameters of the osmotic backwashed membranes were determined using the characterization protocol described in the Materials and Methods section and are presented in Table 1 . The recovery in water flux of the cleaned membranes was attributed to a partial recuperation of the water permeability, $A$. The osmotic backwash reduces the membrane hydraulic resistance by removing SRNOM foulants from the porous support, resulting in hand-cast membranes \#A and $\# \mathrm{~B}$ exhibiting $39.7 \%$ and $40.7 \%$ restoration in $A$, respectively. Note that the structural parameters remained practically unchanged, while salt permeabilities increased slightly $(\sim 28 \%)$ relative to the fouled membranes. Visual inspection of representative images showed a distinct reduction in the yellowish-brown hue of the backwashed membrane, with the lightening of the discoloration especially pronounced for the active layer side (Figure 2). This change in physical appearance suggests that osmotic backwash was effective in cleaning out a substantial fraction of SRNOM foulants deposited in the membrane support layer, including foulant deposited close to the active layer. The pale yellowish-brown tint remaining on the active layer side indicates that the permeation drag induced during the backwash was insufficient to completely remove the foulants adsorbed at the activesupport interface. Lastly, for comparison, the backwashed membrane was soaked in $0.1 \mathrm{M} \mathrm{NaOH}$ for $48 \mathrm{~h}$ to dissolve any residual SRNOM remaining in the membrane porous support. The alkaline immersed membrane appeared virtually of identical whiteness to the pristine membrane on both active and support layer sides (Figure 2).

From the above results, we infer that the osmotic backwash removed the majority of the foulants deposited in the support layer during the second and third phases of PRO fouling, while natural organic matter initially adsorbed at the active-support layer interface (i.e., first phase) was not entirely cleaned out by the permeation drag. Previous studies utilizing atomic force microscopy to measure foulant-membrane and foulantfoulant interactions showed that adhesion forces between natural organic matter foulant and polyamide are greater than between foulant molecules. ${ }^{17,42}$ As such, the permeation drag generated by the osmotic backwash was able to remove the more loosely bound SRNOM in the foulant cake-layer. However, the foulants adsorbed at the active-support interface were cleaned to a much lesser extent. The enduring SRNOM, although small in quantity, possess relatively high specific hydraulic resistance and accounts for the incomplete reversal of fouling effects. The consistent water flux measured during the osmotic backwash (as opposed to an increasing trend) indicates that the recovery of the membrane water permeability was almost immediate. This observation further suggests that the effective cleaning occurred quickly and completely right at the onset of the backwash. The encouraging performance recovery achieved by switching the feed and draw streams for a relatively short interval demonstrates the efficiency of osmotic backwash and highlights its potential application for cleaning membrane support layers fouled in PRO.

Impact of NOM Fouling and Osmotic Backwash on Projected Membrane Power Density. Membrane power density, defined as the power produced per unit membrane 
area, is a key factor affecting the economically viable of PRO power generation. $7,34,35,43,44$ Our previous studies showed that the peak power density attainable is determined by the membrane characteristic parameters - water permeability, $A$, salt permeability, $B$, and structural parameter, $S .{ }^{10,36}$ Fouling of PRO membranes by organic matter, ubiquitous in natural waters, can detrimentally alter transport parameters, while membrane cleaning can partially restore the membrane properties. Hence, SRNOM fouling and osmotic backwash of membranes is expected to impact the power density in PRO energy production. Recent studies found that operating PRO under hydraulic pressure can cause membrane deformation and alter the membrane properties. ${ }^{45-47}$ Hence, in actual PRO operation, the power density will be detrimentally affected by both fouling and membrane deformation. To evaluate the impact of NOM foulants on PRO performance, projected power densities were calculated assuming the membrane properties were not affected by hydraulic pressure. Peak power densities of the pristine, fouled, and cleaned membranes \#A and \#B were determined using eqs 1 and 3 with the model seawater draw and river water feed solutions employed in this study. ${ }^{36}$ The results are presented in Figure 4 (normalized to pristine membrane values), along with the normalized water flux data discussed earlier (data from Figures 3 and S5).
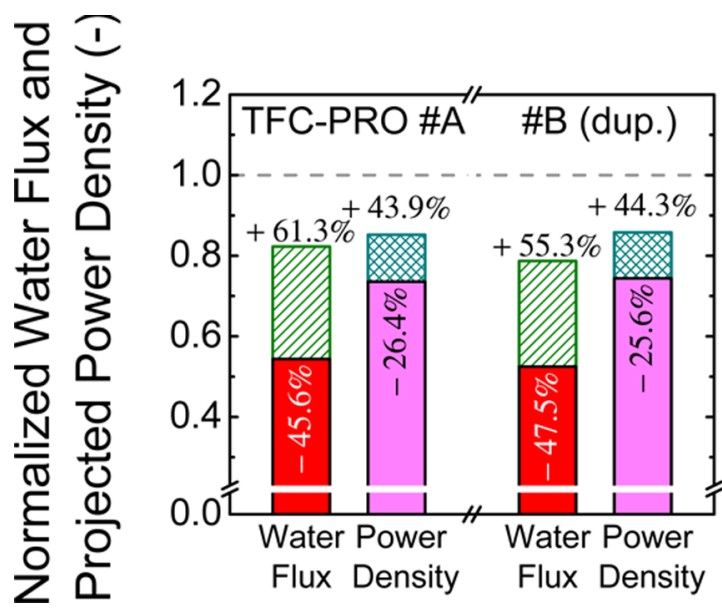

Figure 4. Water flux and projected membrane power density of the hand-cast TFC-PRO membranes \#A and \#B after SRNOM fouling and after osmotic backwash (solid and patterned columns, respectively), normalized with respect to the pristine membrane (horizontal dashed line at 1.0). Labels in the fouled membrane columns indicate the percent change relative to the pristine values, while labels above cleaned membrane columns denote the percent recovery. Experimental conditions are described in Figures $1 \mathrm{~A}$ and 3. The projected power density of pristine membranes \#A and \#B are $4.64 \mathrm{~W} / \mathrm{m}^{2}$ and $4.88 \mathrm{~W} / \mathrm{m}^{2}$, respectively.

Although the transport and structural properties of the handcast membranes \#A and \#B were not tailored for high power density performance, ${ }^{10,36}$ the absolute projected power density values of 4.6 and $4.9 \mathrm{~W} / \mathrm{m}^{2}$, respectively, are still reasonably close to the proposed value of $5 \mathrm{~W} / \mathrm{m}^{2}$ necessary for PRO to be cost-effective. $^{43,44}$ The initial water flux of the fouling experiments was thoughtfully selected to be $\sim 25 \mathrm{~L} \mathrm{~m}^{-2} \mathrm{~h}^{-1}$ to simulate customized membranes with high power density performance in PRO energy generation with natural salinity gradients (projected $\sim 9 \mathrm{~W} / \mathrm{m}^{2}$ ). ${ }^{10}$ In the hand-cast TFC-PRO membranes, fouling of the porous support layer by SRNOM deleteriously increases the membrane hydraulic resistance (i.e., lower $A$ ). Hence, a greater fraction of the osmotic driving force is expended to overcome this additional friction instead of driving water flux. The rate of water permeation across the membrane is impeded and the membrane power density is consequently reduced (eq 3 ). The predicted power density of fouled TFC-PRO \#A and \#B decreased by $26.4 \%$ and $25.6 \%$, respectively. Therefore, SRNOM fouling of porous support in PRO detrimentally constrains the ability of the membrane to convert salinity gradient energy into useful work.

Water permeability of the fouled membrane is partly recovered by the osmotic backwashing cleaning that removed substantial foulants from the porous support. The favorable reduction in membrane hydraulic resistance restored the projected membrane power density by $43.9 \%$ and $44.3 \%$ for TFC-PRO \#A and \#B, respectively. That is, after the brief backwash, the power density was approximately $\sim 0.85$ of the pristine membranes, reasonably close to the original power density. Thus, the cleaned membranes, compared to when fouled, were able to utilize a larger portion of the salinity gradient between seawater and river water for energy generation. The encouraging recovery achieved by a quick osmotic backwash underscores the potential of the technique as an efficient and chemical-free cleaning strategy for membranes in PRO energy production with natural salinity gradients.

\section{IMPLICATIONS FOR POWER GENERATION}

In an actual seawater-river water PRO power generation plant, fouling of membrane porous support layer due to the presence of ubiquitous natural organic matter in the feed stream will diminish the power density. The adverse effects of PRO membrane fouling can be mitigated primarily through three approaches: pretreating the influent streams, using foulingresistant membranes, and cleaning the fouled membranes. Pretreatment of the river water influent to remove natural organic matter and also microorganisms that cause biofouling can be an effective fouling prevention measure, as demonstrated in reverse osmosis desalination applications, but incurs energy and chemical costs. ${ }^{48}$ Intermittent osmotic backwashing of fouled membranes, requiring only nominal pumping energy and posing negligible operational disruption, has the potential to achieve significant performance recovery without chemical use. This study on the efficacy of osmotic backwash showed promising results, but further investigations on a broader range of conditions, for example, the effect of larger permeation drag (i.e., water flux) produced by more concentrated draw solutions such as brine and the minimum backwash duration necessary for effective cleaning, are needed to thoroughly evaluate the suitability of the technique for application in PRO power generation.

Fouling can be alleviated by thoughtful design and/or modification of the PRO membrane to impart fouling resistant properties. Fouling studies on a broader spectrum of foulants (e.g., microorganisms, extracellular polymeric substances (EPS), and colloidal foulants) can improve our understanding of the fouling mechanisms and provide essential insights to guide the fabrication of antifouling membranes. In this study, we show that power density performance deterioration is critically dictated by NOM fouling of the active-support layer interface within the porous support of thin-film composite polyamide membranes. Therefore, efforts can be targeted at reducing the fouling propensity of this susceptible interface through thoughtful modifications of the surface chemis- 
$\operatorname{try}^{42,49,50}$ or incorporation of an additional barrier layer on the back side of the support layer to prevent foulants from entering the porous support. ${ }^{51,52}$ A key challenge here is to achieve fouling resistance enhancements while conserving the membrane transport and structural properties necessary for high PRO power densities. An optimal fouling mitigation strategy will likely be arrived at utilizing combinations, or even all, of the three approaches, while factoring in the capital, chemical, energy, and operational costs to the overall productivity of PRO power generation with natural salinity gradients.

\section{ASSOCIATED CONTENT}

\section{S Supporting Information}

Details of the membrane characterization procedure; discussion on the fabricated TFC-PRO membrane transport and structural parameters; schematic diagram of the laboratory-scale PRO system (Figure S1); SEM cross-sectional micrograph of fabricated TFC-PRO membrane (Figure S2); plot of water flux, salt flux, and reverse flux selectivity in membrane characterization experiments, as a function of the bulk solution concentration difference (Figure S3); plot of water flux as a function of the normalized permeate volume for membranes \#A and \#B (Figure S4); plot of normalized water flux as a function of the normalized cumulative permeate volume for membranes \#A and \#B (Figure S5). This material is available free of charge via the Internet at http://pubs.acs.org.

\section{AUTHOR INFORMATION}

\section{Corresponding Author}

*E-mail: menachem.elimelech@yale.edu, Phone: +1 203432 2789.

\section{Notes}

The authors declare no competing financial interest.

\section{ACKNOWLEDGMENTS}

We acknowledge the support received from the National Science Foundation under Award Number CBET 1232619. We also acknowledge the Graduate Fellowship (to Ngai Yin Yip) made by the Environment and Water Industrial Development Council of Singapore.

\section{REFERENCES}

(1) Chu, S.; Majumdar, A. Opportunities and challenges for a sustainable energy future. Nature 2012, 488 (7411), 294-303.

(2) Logan, B. E.; Elimelech, M. Membrane-based processes for sustainable power generation using water. Nature 2012, 488 (7411), 313-319.

(3) Pattle, R. E. Production of Electric Power by Mixing Fresh and Salt Water in the Hydroelectric Pile. Nature 1954, 174 (4431), 660660.

(4) Yip, N. Y.; Elimelech, M. Thermodynamic and Energy Efficiency Analysis of Power Generation from Natural Salinity Gradients by Pressure Retarded Osmosis. Environ. Sci. Technol. 2012, 46 (9), 52305239.

(5) Dai, A.; Trenberth, K. E. Estimates of freshwater discharge from continents: Latitudinal and seasonal variations. J. Hydrometeorol. 2002, 3 (6), 660-687.

(6) Loeb, S. Osmotic Power-Plants. Science 1975, 189 (4203), 654655.

(7) Achilli, A.; Childress, A. E. Pressure retarded osmosis: From the vision of Sidney Loeb to the first prototype installation - Review. Desalination 2010, 261 (3), 205-211.
(8) Cath, T. Y.; Childress, A. E.; Elimelech, M. Forward osmosis: Principles, applications, and recent developments. J. Membr. Sci. 2006, 281 (1-2), 70-87.

(9) GWI Water Desalination Report, Vol 49, Number 23; June 24, 2013.

(10) Yip, N. Y.; Tiraferri, A.; Phillip, W. A.; Schiffman, J. D.; Hoover, L. A.; Kim, Y. C.; Elimelech, M. Thin-Film Composite Pressure Retarded Osmosis Membranes for Sustainable Power Generation from Salinity Gradients. Environ. Sci. Technol. 2011, 45 (10), 4360-4369.

(11) Chou, S.; Wang, R.; Shi, L.; She, Q.; Tang, C.; Fane, A. G. Thinfilm composite hollow fiber membranes for pressure retarded osmosis (PRO) process with high power density. J. Membr. Sci. 2012, 389, 2533.

(12) Han, G.; Wang, P.; Chung, T.-S. Highly Robust Thin-Film Composite Pressure Retarded Osmosis (PRO) Hollow Fiber Membranes with High Power Densities for Renewable SalinityGradient Energy Generation. Environ. Sci. Technol. 2013, 47, 80708077.

(13) Baker, R. W., Membrane technology and applications, 2nd ed.; J. Wiley: Chichester, 2004; p X.

(14) Mulder, M., Basic principles of membrane technology, 2nd ed.; Kluwer Academic: Dordrecht, 1996.

(15) Bartels, C. R.; Wilf, M.; Andes, K.; Iong, J. Design considerations for wastewater treatment by reverse osmosis. Water Sci. Technol. 2005, 51 (6-7), 473-482.

(16) Mi, B.; Elimelech, M. Chemical and physical aspects of organic fouling of forward osmosis membranes. J. Membr. Sci. 2008, 320 (12), 292-302.

(17) Mi, B. X.; Elimelech, M. Organic fouling of forward osmosis membranes: Fouling reversibility and cleaning without chemical reagents. J. Membr. Sci. 2010, 348 (1-2), 337-345.

(18) Tang, C. Y.; She, Q.; Lay, W. C. L.; Wang, R.; Fane, A. G. Coupled effects of internal concentration polarization and fouling on flux behavior of forward osmosis membranes during humic acid filtration. J. Membr. Sci. 2010, 354 (1-2), 123-133.

(19) Lee, S.; Boo, C.; Elimelech, M.; Hong, S. Comparison of fouling behavior in forward osmosis (FO) and reverse osmosis (RO). J. Membr. Sci. 2010, 365 (1-2), 34-39.

(20) Boo, C.; Elimelech, M.; Hong, S. Fouling control in a forward osmosis process integrating seawater desalination and wastewater reclamation. J. Membr. Sci. 2013, 444, 148-156.

(21) Thelin, W. R.; Sivertsen, E.; Holt, T.; Brekke, G. Natural organic matter fouling in pressure retarded osmosis. J. Membr. Sci. 2013, 438 $46-56$.

(22) She, Q. H.; Wong, Y. K. W.; Zhao, S. F.; Tang, C. Y. Y. Organic fouling in pressure retarded osmosis: Experiments, mechanisms and implications. J. Membr. Sci. 2013, 428, 181-189.

(23) Lee, S.; Elimelech, M. Relating organic fouling of reverse osmosis membranes to intermolecular adhesion forces. Environ. Sci. Technol. 2006, 40 (3), 980-987.

(24) Ang, W. S.; Tiraferri, A.; Chen, K. L.; Elimelech, M. Fouling and cleaning of $\mathrm{RO}$ membranes fouled by mixtures of organic foulants simulating wastewater effluent. J. Membr. Sci. 2011, 376 (1-2), 196206.

(25) Li, Q. L.; Elimelech, M. Organic fouling and chemical cleaning of nanofiltration membranes: Measurements and mechanisms. Environ. Sci. Technol. 2004, 38 (17), 4683-4693.

(26) Averett, R. C. Geological Survey (U.S.) Humic substances in the Suwannee River, Georgia: interactions, properties, and proposed structures; U.S. G.P.O.; For sale by U.S. Geological Survey, Map Distribution, [Washington] Denver, CO, 1994; p ix, 224 p.

(27) Chin, Y. P.; Aiken, G.; Oloughlin, E. Molecular-Weight, Polydispersity, and Spectroscopic Properties of Aquatic Humic Substances. Environ. Sci. Technol. 1994, 28 (11), 1853-1858.

(28) Yip, N. Y.; Tiraferri, A.; Phillip, W. A.; Schiffman, J. D.; Elimelech, M. High Performance Thin-Film Composite Forward Osmosis Membrane. Environ. Sci. Technol. 2010, 44 (10), 3812-3818.

(29) Tiraferri, A.; Yip, N. Y.; Phillip, W. A.; Schiffman, J. D.; Elimelech, M. Relating performance of thin-film composite forward 
osmosis membranes to support layer formation and structure. J. Membr. Sci. 2011, 367 (1-2), 340-352.

(30) Petersen, R. J. Composite Reverse-Osmosis and Nanofiltration Membranes. J. Membr. Sci. 1993, 83 (1), 81-150.

(31) Tiraferri, A.; Yip, N. Y.; Straub, A. P.; Romero-Vargas Castrillon, S.; Elimelech, M. A Method for the Simultaneous Determination of Transport and Structural Parameters of Forward Osmosis Membranes. J. Membr. Sci. 2013, 444, 523-538.

(32) Holloway, R. W.; Childress, A. E.; Dennett, K. E.; Cath, T. Y. Forward osmosis for concentration of anaerobic digester centrate. Water Res. 2007, 41 (17), 4005-4014.

(33) Achilli, A.; Cath, T. Y.; Marchand, E. A.; Childress, A. E. The forward osmosis membrane bioreactor: A low fouling alternative to MBR processes. Desalination 2009, 239 (1-3), 10-21.

(34) Lee, K. L.; Baker, R. W.; Lonsdale, H. K. Membranes for power generation by pressure-retarded osmosis. J. Membr. Sci. 1981, 8 (2), 141-171.

(35) Achilli, A.; Cath, T. Y.; Childress, A. E. Power generation with pressure retarded osmosis: An experimental and theoretical investigation. J. Membr. Sci. 2009, 343 (1-2), 42-52.

(36) Yip, N. Y.; Elimelech, M. Performance Limiting Effects in Power Generation from Salinity Gradients by Pressure Retarded Osmosis. Environ. Sci. Technol. 2011, 45 (23), 10273-10282.

(37) Morel, F. M. M.; Hering, J. G. Principles and applications of aquatic chemistry; Wiley: New York, 1993; p xv.

(38) Perdue, E. M. Ritchie, J. D., 5.10 - Dissolved Organic Matter in Freshwaters. In Treatise on Geochemistry, Heinrich, D. H., Karl, K. T., Eds.; Pergamon: Oxford, 2003; pp 273-318.

(39) Hong, S.; Elimelech, M. Chemical and physical aspects of natural organic matter (NOM) fouling of nanofiltration membranes. J. Membr. Sci. 1997, 132 (2), 159-181.

(40) Belfort, G.; Davis, R. H.; Zydney, A. L. The Behavior of Suspensions and Macromolecular Solutions in Cross-Flow Microfiltration. J. Membr. Sci. 1994, 96 (1-2), 1-58.

(41) Ko, M. K.; Pellegrino, J. J. Determination of osmotic pressure and fouling resistance and their effects of performance of ultrafiltration membranes. J. Membr. Sci. 1992, 74 (1-2), 141-157.

(42) Tiraferri, A.; Kang, Y.; Giannelis, E. P.; Elimelech, M. Superhydrophilic Thin-Film Composite Forward Osmosis Membranes for Organic Fouling Control: Fouling Behavior and Antifouling Mechanisms. Environ. Sci. Technol. 2012, 46 (20), 11135-11144.

(43) Gerstandt, K.; Peinemann, K. V.; Skilhagen, S. E.; Thorsen, T.; Holt, T. Membrane processes in energy supply for an osmotic power plant. Desalination 2008, 224 (1-3), 64-70.

(44) Skilhagen, S. E. Osmotic power - a new, renewable energy source. Desalination and Water Treatment 2010, 15 (1-3), 271-278.

(45) Kim, Y. C.; Elimelech, M. Adverse Impact of Feed Channel Spacers on the Performance of Pressure Retarded Osmosis. Environ. Sci. Technol. 2012, 46 (8), 4673-4681.

(46) She, Q.; Hou, D.; Liu, J.; Tan, K. H.; Tang, C. Y. Effect of feed spacer induced membrane deformation on the performance of pressure retarded osmosis (PRO): Implications for PRO process operation. J. Membr. Sci. 2013, 445, 170-182.

(47) Coday, B. D.; Heil, D. M.; Xu, P.; Cath, T. Y. Effects of Transmembrane Hydraulic Pressure on Performance of Forward Osmosis Membranes. Environ. Sci. Technol. 2013, 47 (5), 2386-2393.

(48) Elimelech, M.; Phillip, W. A. The Future of Seawater Desalination: Energy, Technology, and the Environment. Science 2011, 333 (6043), 712-717.

(49) Park, J. Y.; Acar, M. H.; Akthakul, A.; Kuhlman, W.; Mayes, A. M. Polysulfone-graft-poly(ethylene glycol) graft copolymers for surface modification of polysulfone membranes. Biomaterials 2006, 27 (6), 856-865.

(50) McCloskey, B. D.; Park, H. B.; Ju, H.; Rowe, B. W.; Miller, D. J.; Chun, B. J.; Kin, K.; Freeman, B. D. Influence of polydopamine deposition conditions on pure water flux and foulant adhesion resistance of reverse osmosis, ultrafiltration, and microfiltration membranes. Polymer 2010, 51 (15), 3472-3485.
(51) Wang, K. Y.; Ong, R. C.; Chung, T.-S. Double-Skinned Forward Osmosis Membranes for Reducing Internal Concentration Polarization within the Porous Sublayer. Ind. Eng. Chem. Res. 2010, 49 (10), 4824-4831.

(52) Qi, S.; Qiu, C. Q.; Zhao, Y.; Tang, C. Y. Double-skinned forward osmosis membranes based on layer-by-layer assembly-FO performance and fouling behavior. J. Membr. Sci. 2012, 405-406, 2029. 